Journal of Social and Development Sciences

Vol. 4, No. 11, pp. 494-497, Nov 2013 (ISSN 2221-1152)

\title{
Green Environment awareness Module to Enhance Responsibility and Sensitivity towards the Environment
}

\author{
*Rose Amnah Abd Rauf, Mohamad Sattar Rasul \\ University of Malaya, Malaysia \\ University Kebangsaan Malaysia, Malaysia \\ *rose_amnah@hotmail.com
}

\begin{abstract}
All forms of life in this world needs a healthy environment in which all living things interact continuously. Extensive use of the natural resources by humans resulted in the depletion of the environment. Thus, it is essentials that humans are made aware and take responsibility of protecting the environment for the present and future generations. To achieve this, environmental education are essential to encourage and educate citizen so that they are aware and play an active part in protecting the environment by making informed decisions on any actions taken. Education is the means to impart and develop the appropriate knowledge, skills and values in order to understand what human's activities and action have done to the environment. Thus, sensitivity towards issues of the environment will emerge or arise within individual and in turn will nurture responsible attitude on protecting the environment. The aim of this study is to develop a conceptual framework of Green Environment Awareness Module. Special features in this module are providing informative, educative and reliable information about the environment which incorporate the use of QR-Code for easy retrieval. Development of the module using the Modified Delphi Technique was carried out.
\end{abstract}

Keywords: Educational process, green environment, awareness, Qr-Code

\section{Introduction}

Environmental Education in Malaysia began in 1998 with the publication of Teachers' Handbook for Environmental Education across the Curriculum for teachers in primary and secondary schools (Zohir \& Nordin (2007). Efforts to inculcate values on environment are supported by government agencies such as the Department of Environment who actively organizes various environmental activity involving school children. The effectiveness of these initiatives amongst school children is still not much known. Students' environmental awareness is important to investigate because environmental education introduced to school children does not necessarily produce the desired learning effect especially when they leave school. In the midst of creating new products of science and technology we forgot to sustain a healthy and harmonious environment and lost our sense of responsibiltiy towards the environment. Jamilah (2011) in her study found that the level of awareness among the community in Malaysia is still quite low and many put the responsibility of sustaining the environment to the government. For sustainable development, one should put emphasis on increasing environmental awareness among their citizens. Awareness of environment within Malaysians is low due to level the lack of awareness on the importance of preserving and conserving environmental resources. Malaysia's recycling rate (5\%) is low when compared to other countries such as Switzerland (52\%), Austria (64\%). Germany (62\%) in 2010. Housing and Local Government Ministry has targeted recycling rate achievement in Malaysia at the rate of $22 \%$ by 2020 (Department of Environment, 1997 in Jamilah, 2011) but it is difficult to achieve if individual awareness of protecting the environment still remains unchanged (Jamilah, 2011). Education is seen as an important and best option to educate new generations toward sustaining the environment. In the 1977 Tbilisi Declaration, the United Nations called for programs to foster environmental awareness, provide opportunities and skills for environmental protection, and create new patterns of behavior. Factors that drive innovation in the curriculum is the needs of the community and the country, the development of science and technology itself and the development of philosophy, psychology and educational theory. Reserch done by Geok, Kim and Chuan (1998) in Jamilah (2011) showed that students acquire information and knowledge about the environment from sources such as magazines, newspapers and electronic media outside of school. Thus, the need to find an alternative approach and resource to provide environmental education for school children besides given in the curriculum. 
Statement of Problem: Intrinsic sense of responsibility and awareness can be awakened through education, teachers as the main mediator to the present and future generation in order to disseminate knowledge and indirectly will assist in comprehending the environmental issues locally and globally. Teachers should have the right attitude and motivation to realize the goals of environment education. The government and higher institution should play their role and support to teachers by equipping them with knowledge, environmental pedagogy, materials and learning sources in order for them to impart and inculcate the desired understanding and attitude of present and future generations towards the environment. Studies revealed that the level of environmental awareness among the Malaysian community have not reached a satisfactory level (Aini, 2011). We will not be able to see the impact of environmental education programs on young people because they will not be in the position to make decision (Evans, Gill \& Marchant, 1996) but the process of caring for the environment should start from the young because if they practice how to care for the environment until they are in the right position to make decision, then, maybe the environment might not be in need of much help. Thus, this study tries to come up with a conceptual framework for green environment awareness so that it can be used to develop a Green Environment Awareness to facilitate attitudes and practice amongst Malaysian.

Environment is now increasingly vulnerable towards damage and natural resources are depleting rapidly due to the increase in population and rapid economic growth in many countries. Thus, education is very important to ensure that environmental awareness which covers ethics, values, attitudes, skills and behavior of the public are consistent with sustainable development. The involvement of the public is very important in decision making on environmental issues. Public's attitudes can be change through formal and informal education so that they have the ability to assess and to address the environmental issues that arise (Pudin, Tagi \& Periasamy, 2005). In order to create and embed awareness of the importance of sustaining the environment children should be educated with vast authentic materials to the abuse of the environment made by men. This can be achieved through a module giving them unlimited information and by giving them the first hand supply of information by the click of a phone or device. The use of QR code is the most suitable technology to support this because QR code can contain massive information in a small square pattern. There is no need to use papers and to bring thick books anywhere. QR code will enable us to learn and educate about the environment anywhere and anytime where it is permissible.

Objectives of Study: The aim of this study is to develop a conceptual framework of Green Environment Awareness Module using QR-Code. This module in turn will be used by teachers or anyone interested in environment education as a supporting material or source to help them to foster a sense of responsibility and embed sensitivity towards issues of the environment.

\section{Development Process of the Green Environment Awareness Conceptual Framework}

Underpinning theories: The development of the Green Environment Awareness Module using QR-Code is based on the Causal Model of Resource-Consumption Behavior by Gardner \& Stern (1996) which consist of two main types of barriers that can keep people from acting on pro-environmental attitudes. The first is that any break in the chain between attitudes and behavior because of absence of appropriate knowledge can keep pro-environmental attitudes from creating action. According to this Model, the barriers exist within individuals and intervention should be aimed at individuals. Second, the external barriers of the individuals which include the socioeconomic background, technology, social and political institutions, and economic forces can prevent the forming of pro-environmental. Thus, this module aimed at providing massive information to increase and enrich individual knowledge so that it will awaken and initiate change of behavior. And secondly, the module will use the concept of m-learning in module hat is QR-Code to make the module interesting and motivates self-regulated learning. Individuals need information or knowledge to act or behave effectively in an environmental situation because there is a connection between behavior personal experiences. The lack of information or knowledge is considered as an internal barrier to action. Studies showed that by giving information have an effect on attitude change but the type and method of giving information has different effect on the attitude. Just by giving simple, plain information was shown to give little effect on the attitude, thus consideration should be given to how the information will be given.

The learning theories underpinning the development of the module are Mobile Learning (ML) and SelfRegulated Learning (SRL). SRL gives freedom for individual to pursue learning without constant control from the teacher. Students have the freedom to make decisions on how to learn, what to learn, make decision and implementing it. According to Zimmerman and Schunk (1989), SRL is self-generated 
thoughts, feelings and actions which are systematically oriented toward the goal of student achievement in itself. There are many definition of mobile learning (m-learning), but the definition given by Advance Distributed Learning (ADL) suggest that m-learning should be viewed as a one of the source for a learner to increase their knowledge through the use of never ending technology that is available regardless of the time and place. M-learning can be used formally or informally in all modes of learning. M-learning provides an alternative for learning other than in the classroom; it goes beyond the ordinary learning environment with fixed classes and time. It gives the learner a sense of freedom and power to choose when is the best time to study or access knowledge and gain knowledge (West, 2013).

The Development process: The above theories were incorporated into a framework from which the module was developed. The content of the module based on the framework were obtained from experts using the Delphi Method. Figure 1 shows the conceptual framework of the Green Environment Awareness Module using QR-Code.

\section{Figure 1:}

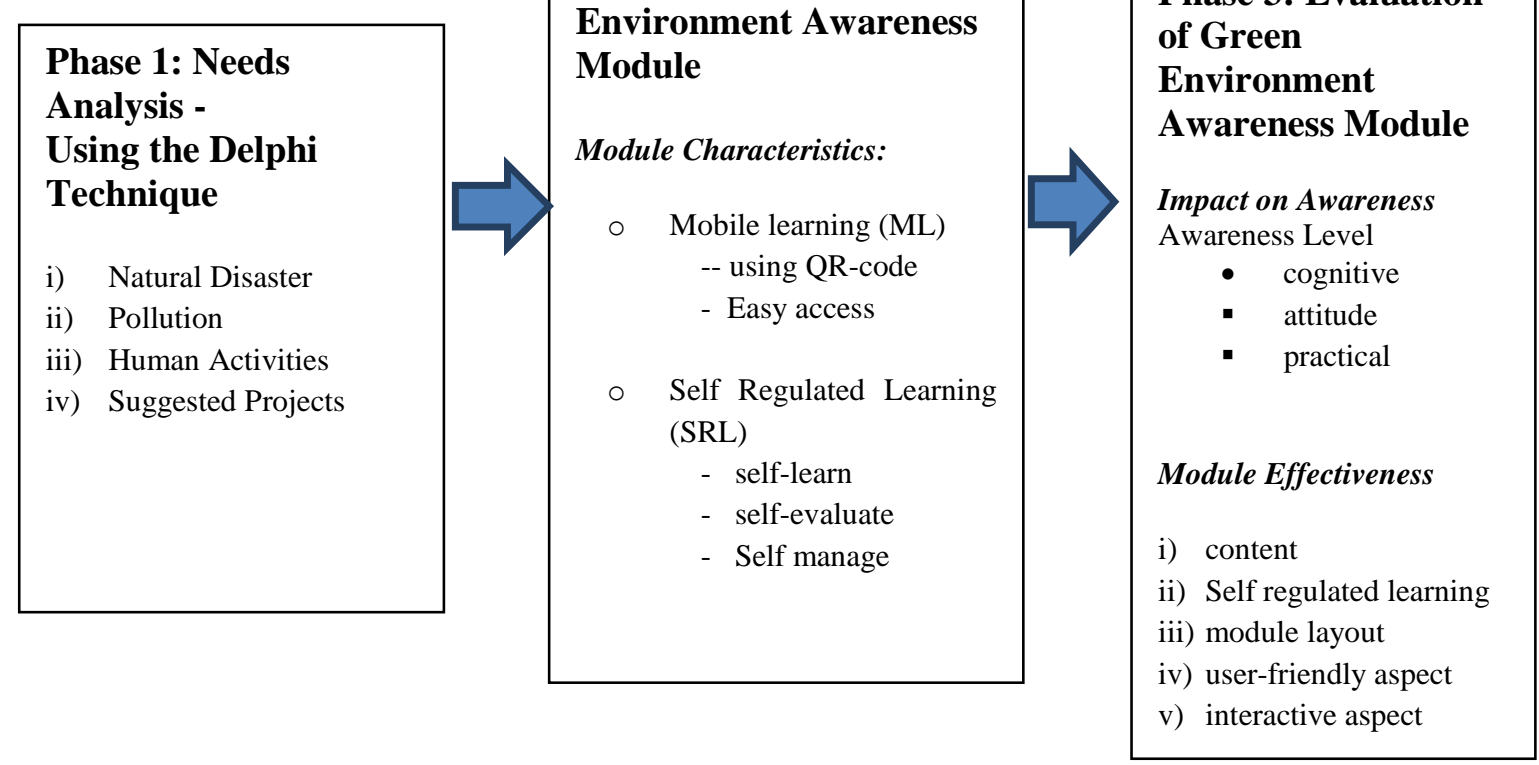

Phase 1 is the needs analysis in which to identify problems related to awareness for green environment. Using the Delphi technique, information were elicited from experts consists of 15 teachers and 2 environmental officer to determine the content of the module according to the guideline of the focus of the module. In Phase 2 is the development of module using the input from phase 1 to construct the design of the module? The design of the module taking into account the underpinning theories to create the activities and information of the module. The combination of m-learning and SRL is a technology network in education has great potential to advance the interaction between teachers and students (Psaromiligkos \& Retalis, 2003). The information of environmental issues is given in text, graphics and source which students can access by themselves using the QR-Code. At the end of the module, students are required to do the self-evaluation and small and manageable projects on environment sustainability that they can do on their own. Through these projects, the students will come to realize their part in sustaining the environment by doing little things. Phase 3 is the evaluation phase. The outcome of the module is evaluated on its impact on awareness and effectiveness of the module.

\section{Conclusion}

It is difficult to change ethics and values of individuals towards the environment but through practice it will eventually turn into habit and hopefully affect their ethics and values in the long run. Education is the means to change the attitudes of individuals on environment. Studies on environmental attitudes and behaviors indicate that a change of attitude alone is not enough to sustain the environment because they are considered as predictive action in similar situations. But attitude will lead to behavior and behavior will lead to practice and in turn will become a habit. This can be accomplished when strong barriers, internal and external barriers to action are removed. Individual's action depends on their beliefs, knowledge and experience of an environmental situation or condition. Lack of knowledge because of 
minimum information and exposure to the situation at hand will affect an individual action on the environment. But just by giving information is not enough, we need to tie it directly to people's behavior by giving them the complete information and knowledge to them and make sense of the information provided. Thus, it will create a personal commitment in the individual when they realize the destruction made by humans. The cognitive dissonance theory indicated that when an individual act upon something without expecting any reward is an indicator the individual own choice of action. Individual who act on their own because of instinct or internal responsibility is likely to behave the same way even after the situation has been resolve. The intervention or message of green environment awareness should be given at a suitable and right time would make an impact on the behavior and attitude of the individual.

Acknowledgement: This project is funded by University of Malaya through UMRG grand project no: RG345-12HNE, total grand RM29, 900.

\section{References}

Aini, R. (2011). Kesedaran kitar semula masih rendah. Kosmo Harian, January 22.

Evans, S. M., Gill, M. E. \& Marchant, J. (1996). Schoolchildren as educators: the indirect influence of environmental education in schools on parents' attitudes towards the environment. Journal of Biological Education, 30(4), 243-248.

Gardner, G. T. $\&$ Stern, P. C. (1996). Environmental problems and human behavior (2nd Ed.). Boston, MA: Pearson Custom P ublishing.

Jamilah, A. (2011). Pengetahuan Sikap dan Amalan Masyarakat Malaysia terhadap Alam Sekitar. MALIMSEA Journal of General Studies, 13, 139-154

Zohir, M. A. \& Nordin, A. R. (2007). Pendidikan alam sekitar di sekolah: komitmen guru. Diges Pendidik, 7(2), 74-81.

Psaromiligkos, Y. \& Retalis, S. (2003). Re-evaluating the electiveness of a web-based learning system: A comparative case study. Journal of Educational Multimedia and Hypermedia, 12(1), 5-20.

Pudin, S., Tagi, K. \& Periasamy, A. (2005). Environmental education in Malaysia and Japan: A comparative assessment. Paper presented at the Education for a sustainable future international conference,

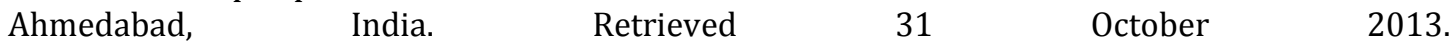
http://www.ceeindia.org/esf/download/paper20.pdf

West, D. M. (2013). Mobile Learning: Transforming Education, Engaging Students, and Improving Outcomes. Retrieved 31 October 2013 from www.brookings.edu/research/papers/2013/09/17mobile-learning-education-engaging-students-west.

Zimmerman, B. J. \& Schunk, D. H. (1989). Self-regulated learning and academic achievement: Theory, research, and practice. New York: Springer-Verlag. 